\title{
Estimation of convergence boundary location and velocity between tectonic plates in northern Hokkaido inferred by GNSS velocity data
}

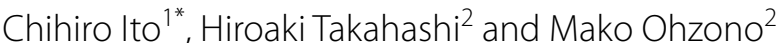

\begin{abstract}
The present location of the tectonic boundary and the convergence rate between the Amur and Okhotsk plates in northern Hokkaido, Japan, were herein estimated from the velocity field using data from a continuous GNSS network. The observed velocity profiles are in agreement with the theoretical ones calculated from a tectonic block collision model. The estimated kinematic boundary agrees with both geological and seismic boundaries. Overall, this indicates that the geological boundary acts like a mechanical one. The calculated convergence velocity of $14.0-16.5 \mathrm{~mm} /$ year is consistent with predictions from regional plate motion models and suggests that a considerable amount of interplate convergence is in progress along this boundary. Deep crustal seismicity is also in agreement with the estimated elastic thickness of 20.5-25.5 km. The non-occurrence of large earthquakes during the past several centuries, and the estimated convergence velocity suggest that there is a high potential for a large event in the near future.
\end{abstract}

Keywords: GNSS measurements, Collision zone, Amur plate, Crustal deformation, Hokkaido

\section{Introduction}

Crustal activity in northeastern Asia is controlled by the interaction among three major plates (the Eurasian, North American, and Pacific plates), and other small tectonic blocks (the Okhotsk, Amur, and Philippine Sea plates) (Fig. 1) (Wei and Seno 1998; Heki et al. 1999; Jin et al. 2007). Crustal deformation in Japan occurs at particularly high rates due to the presence of many plate boundaries (Sagiya et al. 2000; Loveless and Meade 2010).

The kinematic feature of the plates in northeastern Asia (e.g., the location and convergence velocity between the Japanese Islands and the continental plate) remains controversial. By analyzing earthquake hypocenters and mechanisms, Chapman and Solomon (1976) indicated that the boundary between the Eurasian and the North American plates should extend from central Sakhalin to

\footnotetext{
*Correspondence: chr-0521-i@eis.hokudai.ac.jp

${ }^{1}$ Institute of Seismology and Volcanology, Graduate School of Science,

Hokkaido University, Sapporo, Japan

Full list of author information is available at the end of the article
}

central Hokkaido. The focal succession of destructive large earthquakes along the eastern margin of Japan Sea up to Sakhalin (e.g., the $1983 M_{\mathrm{w}} 7.7$ and the $1993 M_{\mathrm{w}}$ 7.8 earthquakes) might indicate the existence of a major boundary (e.g., Nakamura 1983) (Fig. 1). Several models that describe the plate kinematics in northeastern Asia according to the slip vectors of earthquake focal mechanisms suggest the existence of the Okhotsk and Amur micro-plates (Seno et al. 1996; Wei and Seno 1998). The motion of the Amur plate has been observed successfully using a geodetic network (Takahashi et al. 1999; Heki et al. 1999). Recent geodetic data, however, indicate a complex crustal deformation field in this region (Shestakov et al. 2011).

Northern Hokkaido, the northernmost part of Japan, is believed to be at the boundary between the Amur and Okhotsk plates. The high seismicity in the region, characterized by dominant east-west reverse fault mechanisms, might reflect plate convergence. Over a century of conventional geodetic measurements also suggest an eastwest compressional strain field (Geospatial Information 


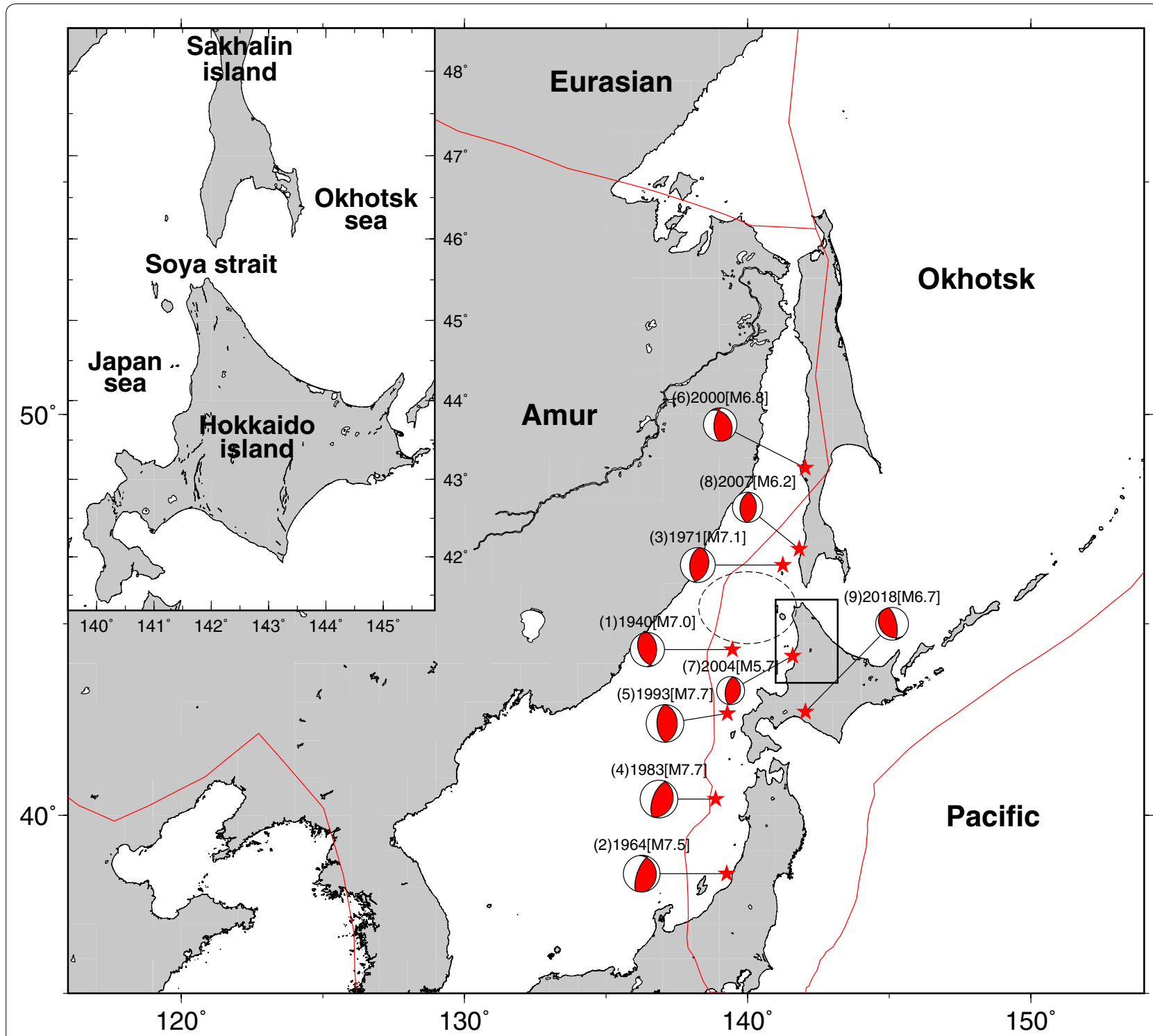

Fig. 1 Tectonic map of northeast Asia. The red line indicates a plate boundary model (PB2002) by Bird (2003). Stars indicate the epicenters of large earthquakes along the eastern margin of the Japan Sea. The moment tensor solutions are from Fukao and Furumoto (1975) for (1) and (3), from Abe (1975) for (2), and from the Global CMT Project (2019) for (4)-(9). A black broken circle indicates the absence of large earthquakes. The study area is indicated by a black solid line

Authority of Japan 1997). Loveless and Meade (2010) extrapolated a maximum convergence velocity of $13 \mathrm{~mm} /$ year using GNSS velocity data for a given boundary. Vasilenko and Prytkov (2012) estimated a convergence velocity of $10.0-13.1 \mathrm{~mm} /$ year along a priori given faults in southern Sakhalin, i.e., the region immediately north of Hokkaido. However, the location of the plate boundary has not been specifically defined through geodetic data yet.

A simultaneous estimation of the location of the plate boundary and of the convergence velocity is desirable, so that a better insight into the plate convergence properties can be obtained. This simultaneous estimation will provide evidence for the investigation of the relationship of such properties with other geophysical and geological data. In this study, we estimate plate convergence parameters between the Amur and Okhotsk plates in northern Hokkaido using a nationwide GNSS network. 


\section{Data and methods GNSS velocity data}

We applied horizontal velocity data acquired by GNSS to crustal deformation modeling. We used the F3 daily solutions of the GEONET in Japan (nationwide continuous GNSS network), provided by the Geospatial Information Authority of Japan (Nakagawa et al. 2009). Data from January 1, 2008, to December 31, 2010, were employed in this study to minimize and discard the postseismic effects of the 2003 Tokachi-oki M 8.0, and the 2011 Tohoku-oki M 9.0 interplate earthquakes (e.g., Itoh and Nishimura 2016; Ozawa et al. 2011). It was assumed that the observed coordinate time series included some effects of steady plate motion, interseismic coupling and post-seismic signal of the 2003 event. No corrections for these factors were, however, applied to velocity data while evaluating collision kinematics involving these conditions.

The horizontal velocities of the east-west and northsouth components at each station were estimated by fitting the following formula to the daily coordinate time series using the least square procedure

$$
u(t)=a t+b+\sum_{n=1}^{2}\left(c_{n} \sin (2 \pi n t)+d_{n} \cos (2 \pi n t)\right)
$$

where $u(t)$ is the coordinate of specific component at the time of $t$ (in years), $a$ the coefficient of the linear velocity, $b$ the constant of the function, $c_{1}, d_{1}$ are the coefficients of the annual variation, and $c_{2}, d_{2}$ the coefficients of the semi-annual variation, respectively. Vertical velocity was not considered in our study because its accuracy was lower than that of horizontal velocity.

The F3 coordinates used in this study were based on the ITRF2005 reference frame (Altamimi et al. 2011; Nakagawa et al. 2009). The estimated velocities were transformed into the Eurasian plate-fixed reference frame using the ITRF2005 plate motion parameters. Figure 2 shows the horizontal velocity field in Hokkaido with respect to the Eurasian plate. All stations were moving in a west-northwestward direction with respect to the Eurasian plate. Although observed velocities include the effect of the interplate coupling of the subducting Pacific plate, the effect is thought to be limited in this study area (Hashimoto et al. 2009). Next, the velocity field was converted to the station 0863 fixed reference frame to focus on the deformation features resulting from collision in this region. We used this reference frame velocity data in the subsequent crustal deformation modeling.

\section{Crustal deformation modeling}

The crustal deformation field was modeled by using Shimazaki and Zhao's (2000) scheme. Accordingly, the displacement field of the collision zone was represented as a superposition of rigid plate motion and elastic deformation produced by a vertical, tensile open fault along the collision boundary. The collision boundary was modeled as a line with infinite length and vertical dip with the depth. The theoretical horizontal velocity $V_{x}$ at a distance of $x \mathrm{~km}$ from the boundary is given by the formula:

$$
V_{x}=\frac{V}{\pi}\left(\frac{x H}{x^{2}+H^{2}}-\tan ^{-1} \frac{x}{H}+\frac{\pi}{2}\right)
$$

where $V$ and $H$ represent the plate convergence velocity and the thickness of the elastic layer, respectively. The boundary condition $V_{x=\infty}=0$ is assumed. The free parameters are the velocity $V$, the elastic thickness $H$, and the distance $x$. The last is a function between the longitude and latitude of each GNSS site, and the nodal location and strike of a given boundary. The observed velocities were projected onto the direction perpendicular to the given boundary geometry.

A grid search procedure was applied to determine the best fit parameters. The Chi-squared value $\chi^{2}$ for the unknown parameters $H$ and $V$ in Eq. (2) was evaluated by the following formula for the given boundary location grids and strikes,

$$
\chi^{2}=\sum_{i=1}^{N} \frac{\left(V_{i}^{\mathrm{cal}}-V_{i}^{\mathrm{obs}}\right)^{2}}{\sigma_{i}^{2}}
$$

where $V_{i}^{\mathrm{cal}}$ and $V_{i}^{\mathrm{obs}}$ represent the model calculated and the observed velocities at the $i$ th station, respectively, $\sigma_{i}$ the measurement error, and $N$ is the number of the observation points. Estimation errors were estimated using the procedure indicated in Vasilenko and Prytkov (2012).

The grid searching ranges were set as follows: the nodes of boundaries were distributed in the longitudinal range of $141^{\circ} \mathrm{E}-143.18^{\circ} \mathrm{E}$ and latitudinal range of $43.5^{\circ} \mathrm{N}-45.6^{\circ} \mathrm{N}$, with a grid interval of $0.01^{\circ}$. Strike, velocity, and thickness intervals were taken as $0.1^{\circ}, 0.1 \mathrm{~mm} /$ year, and $0.1 \mathrm{~km}$, respectively. We applied this procedure for three areas to confirm the regional differences: the northern area $\left(44.55^{\circ} \mathrm{N}-45.6^{\circ} \mathrm{N}\right)$, the southern area $(43.5-$ $\left.44.55^{\circ} \mathrm{N}\right)$, and the entire area $\left(43.5-45.6^{\circ} \mathrm{N}\right)$, as shown in Fig. 2. Data from GNSS stations at 17 sites, 27 sites, and 44 sites, respectively, were used for the estimations.

\section{Results and discussion}

The best fit geometry of the boundaries for the three regions is shown in Fig. 3a and is reported in Table 1. The estimated boundaries in the three areas indicated approximately north-south strike directions. The comparison between observed and calculated velocities 


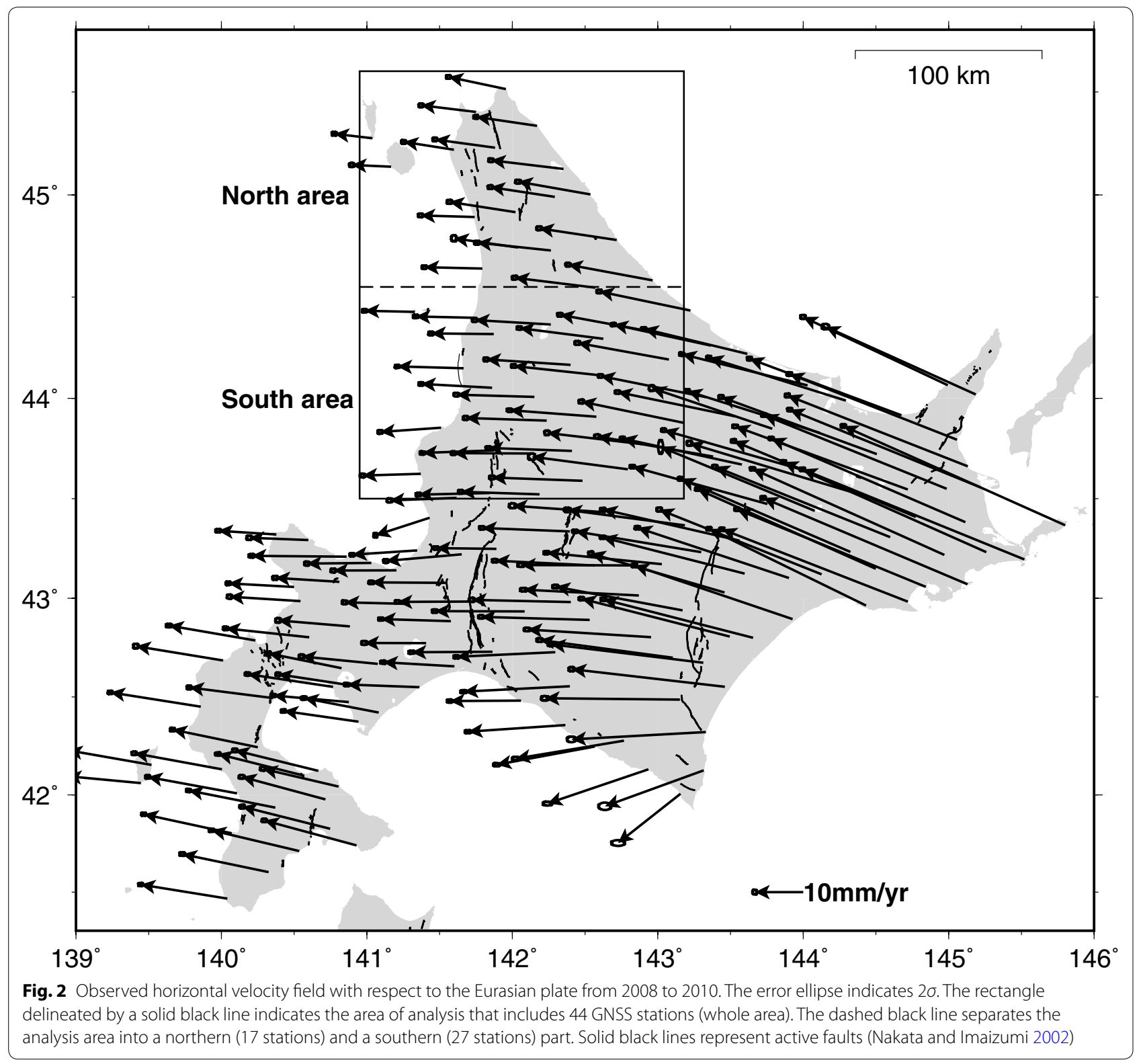

(Fig. 3b) suggests that the estimated models in the northern and southern regions are more consistent with the data. This is also in agreement with the estimation of the $\chi^{2}$ error (see Table 1). The error mapping of $\chi^{2} /(N-4)$ values shown in Fig. 3c indicates the status of constraint of velocity and elastic thickness parameters in the model.

\section{Comparison with seismicity and geological boundary}

Figure 4 shows the spatial distribution of the hypocenters of earthquakes that occurred between 1997 and 2016 (Japan Meteorological Agency 2019). This suggests that a clear seismically active zone extends along the north-south direction. Although there is a spatial gap due to the simplicity of the dislocation model used in this study (Shimazaki and Zhao 2000) and low density of GNSS stations, our results for the three areas are roughly consistent with the seismological boundary. Tamura et al. (2003) and Takahashi and Kasahara (2005) indicated that the eastern margin of this seismically active zone corresponds to a major geological boundary of the late Cretaceous Hidaka belt and the late Jurassic Sorachi-Yezo belt. A clear gravity anomaly has also been announced along this geologic boundary (Geological Survey of Japan 2015). The geodetic boundary estimated in our study agrees well with independent seismic and geologic boundaries. These facts 

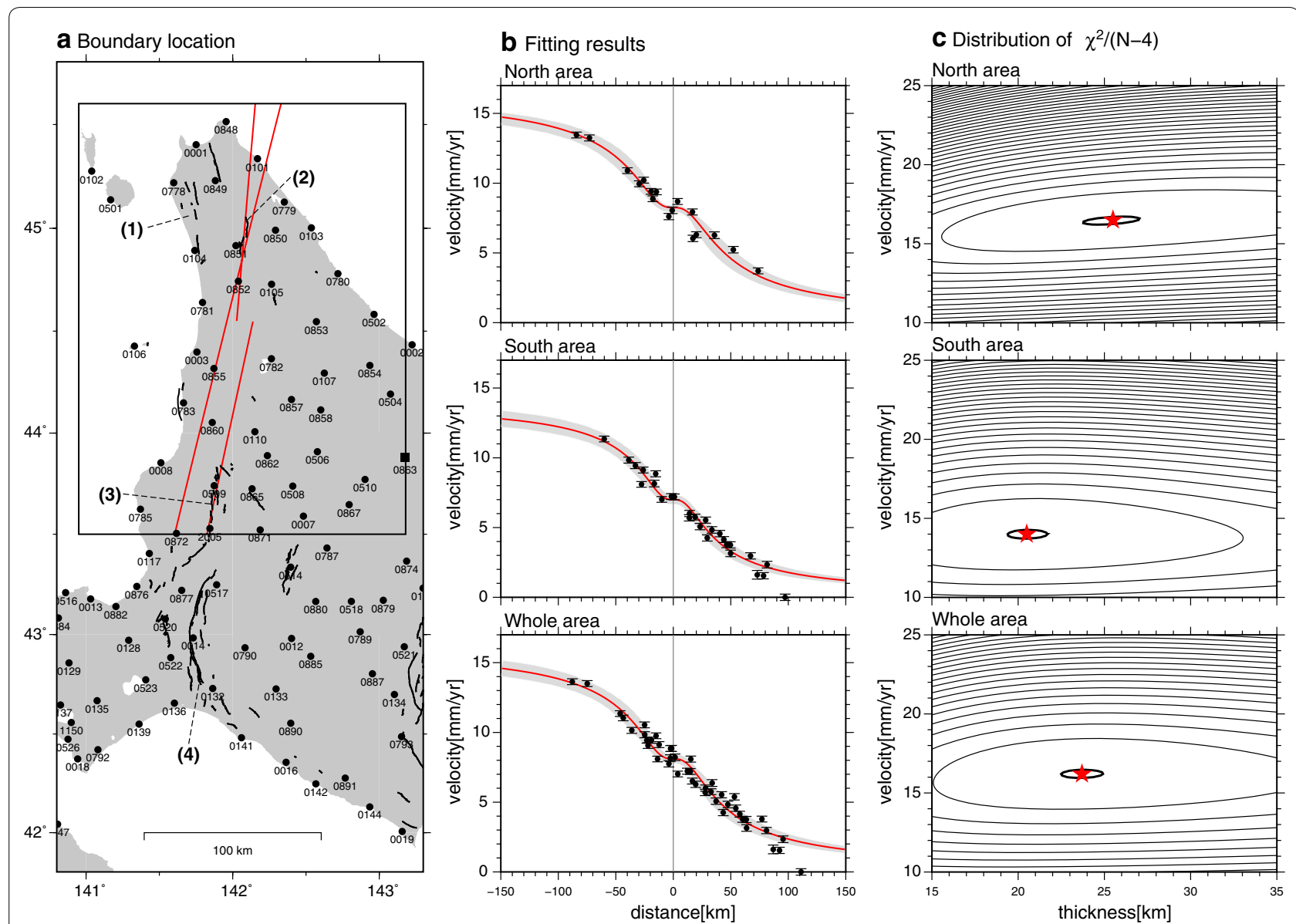

Fig. 3 a Locations of GEONET stations used in this study. Red lines in the northern, southern, and whole areas are the estimated boundaries in each area of analysis. Active faults (Nakata and Imaizumi 2002) are shown by black lines; (1) Sarobetsu, (2) Toikanbetsu, (3) Mashike-Toen, (4) Ishikari-Teichi-Toen faults. b Velocity profiles of three respective area plotted against the distance from the boundary. The red curves and black dots are the theoretical best fit functions and the observed velocities with $2 \sigma$ errors, respectively. The gray shaded areas represent the range of $2 \sigma$ model errors. c Distribution of $\chi^{2} /(N-4)$ value with varying convergence velocity and elastic thickness of three areas with the best fit boundary location and strike. Red stars show the least error domain. The bold black lines indicate a confidence interval of 95\%. The gray lines are drawn at regular intervals of 100 units

Table 1 Results of modeling of the collision between Okhotsk and Amur plates

\begin{tabular}{lllllll}
\hline Area & $\boldsymbol{N}$ & Latitude $\left[{ }^{\circ} \mathbf{N}\right]$, longitude $\left[{ }^{\circ} \mathrm{E}\right]$ & Strike $\left[\mathrm{N}^{\circ} \mathrm{E}\right]$ & $\begin{array}{l}\text { Convergence velocity } \\
(\mathbf{m m} / \text { year })\end{array}$ & $\begin{array}{l}\text { Elastic thickness } \\
(\mathbf{k m})\end{array}$ & $\boldsymbol{X}^{\mathbf{2}} /(\boldsymbol{N}-\mathbf{4})$ \\
\hline North & 17 & $45.075,142.09_{-0.01}^{+0.02}$ & $5.0_{-1.8}^{+2.8}$ & $16.5_{-0.2}^{+0.1}$ & $25.5_{-1.4}^{+1.4}$ & 37.642 \\
South & 27 & $44.025,141.98_{-0.02}^{+0.02}$ & $12.4_{-1.8}^{+1.9}$ & $14.0_{-0.2}^{+0.2}$ & $20.5_{-1.1}^{+1.2}$ & 33.222 \\
Whole & 44 & $44.550,141.96_{-0.02}^{+0.02}$ & $12.4_{-1.1}^{+1.1}$ & $16.2_{-0.2}^{+0.2}$ & $23.7_{-1.2}^{+1.2}$ & 39.627 \\
\hline
\end{tabular}

$\mathrm{N}$ is the number of stations in each area. Latitude $\left[{ }^{\circ} \mathrm{N}\right]$ and longitude $\left[{ }^{\circ} \mathrm{E}\right]$ represent the fix points of the boundary. Strike $\left[\mathrm{N}^{\circ} \mathrm{E}\right]$ is the angle of the boundary from north to east. Errors of each parameter are shown as $2 \sigma$ intervals

strongly suggest that the geological boundary might act as a mechanical boundary.

In northern Hokkaido, the Sarobetsu fault zone, which has major active faults, is located on the Japan Sea side (Fig. 3a). This active fault is assumed to be an east-west compressional reverse fault (Headquarters for Earthquake Research Promotion 2019). The long-term earthquake occurrence probability of the $M_{\mathrm{w}} 7.6$ event is $4 \%$ over 30 years (Headquarters for Earthquake Research Promotion 2019), which is comparatively high for Japan. 


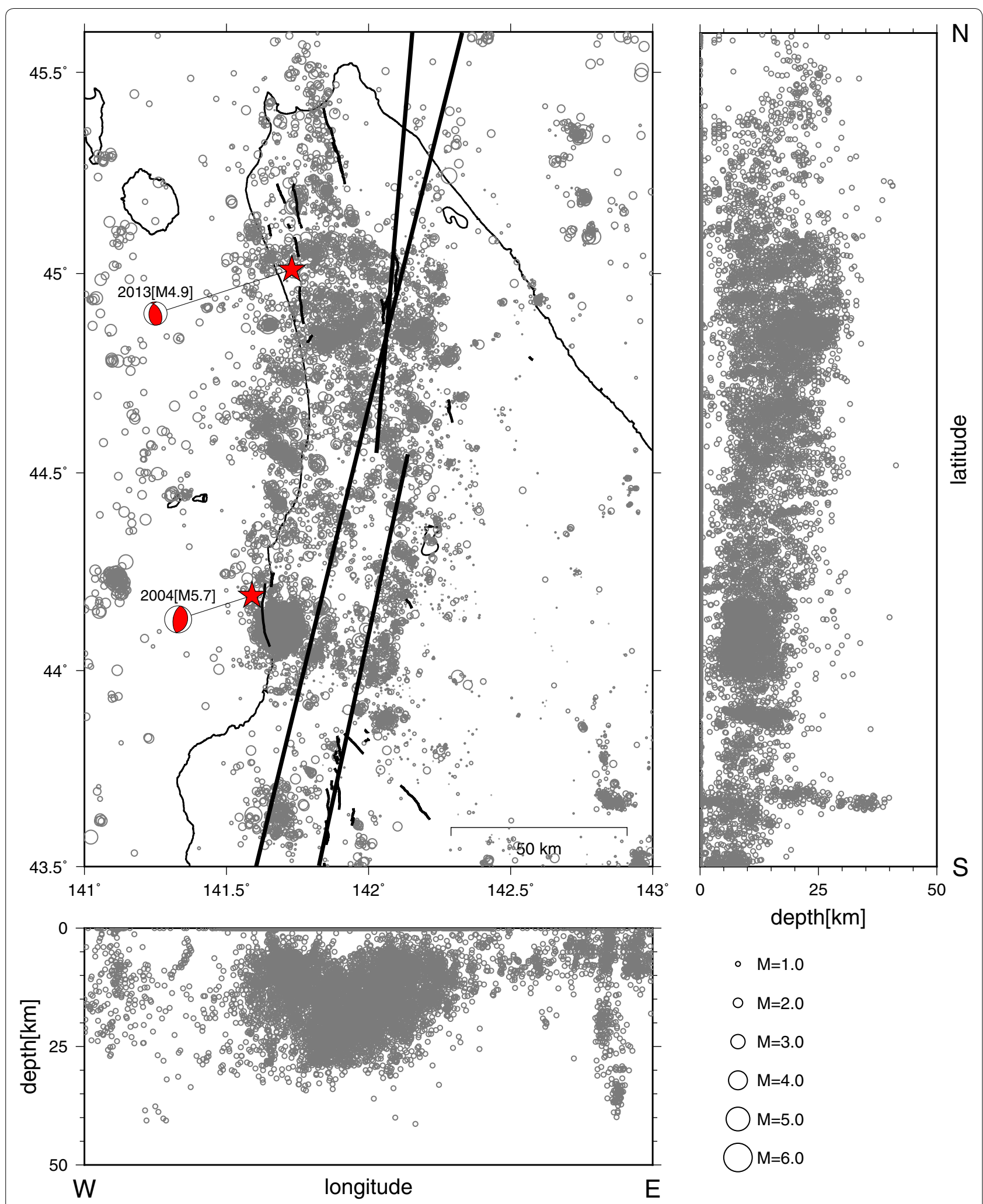

Fig. 4 Seismicity map of northern Hokkaido. The epicenters of earthquakes from 1997 to 2016 are plotted based on the catalog obtained from the Japan Meteorological Agency (2019). The solid lines indicate the estimated location of the boundary in each area (same as in Fig. 3a) 
The estimated locations for both the northern and the whole area are roughly consistent with another active fault-the Toikanbetsu fault. The existence of a slow slip event around the fault is observed, which might suggest a high stress regime (Ohzono et al. 2015). Our estimation also suggests successive stress buildup in these active fault zones.

\section{Thickness of the elastic layer}

The estimated elastic thicknesses are $25.5 \mathrm{~km}$ in the northern part, $20.5 \mathrm{~km}$ in the southern part, and $23.7 \mathrm{~km}$ according to the analysis of the whole area, respectively (Table 1). These values are significantly larger than in other regions of the Japanese Islands, even by accounting for the estimation errors (e.g., Shimazaki and Zhao 2000).

The distribution of the hypocenters in this region indicates deep earthquake foci at $20-30 \mathrm{~km}$ depth (Fig. 4). The estimated thicknesses correspond to the cutoff depth of seismicity. The D90 depth in this region is estimated in about 20-25 km (Omuralieva et al. 2012). For northern Hokkaido, the recorded heat flow is lower than for other parts of the island (Tanaka 2004). This agrees with the fact that the depth of earthquakes is relatively deep. Estimated thick elastic layer might reflect above geophysical features. Vasilenko and Prytkov (2012) estimated the elastic thickness in 20-36 km in the southern part of Sakhalin. Despite the lesser convergence level of elastic thickness estimation, as shown in Fig. 3c, our results are roughly consistent with that in southern Sakhalin. This might indicate the possibility that the tectonic conditions in northern Hokkaido and southern Sakhalin are the same.

\section{Convergence velocity}

The estimated convergence velocities in this study are $16.5 \mathrm{~mm} /$ year in the northern part, $14.0 \mathrm{~mm} /$ year in the southern part, and $16.2 \mathrm{~mm} /$ year for the whole area. As we mentioned in the "GNSS velocity data" section, observed velocity data probably include the effect of the interplate coupling of the Pacific plate, especially in the southern part, due to closer distance from the Kuril Trench. For example, Hashimoto et al. (2009), which estimate interplate coupling from GNSS data, show the gradual decay of velocity field affected by the interplate coupling from the Kuril Trench to northern Hokkaido. Assuming this condition has been lasted until the present, the difference of velocity due to the effect of interplate coupling is only a few $\mathrm{mm}$ /year in our study area. Our estimated convergence velocity might be overestimated about $7 \mathrm{~mm} /$ year at the southern part because it includes the effect of plate interaction. Therefore, it is thought that the velocity field in the northern part, which is distant from the trench, has less effect of interplate coupling and reflects the convergence between the Amur and Okhotsk plate. Heki et al. (1999) predicted a regional convergence velocity of $16 \mathrm{~mm} /$ year in northern Hokkaido due to the relative motion between the Amur and Okhotsk plates from a plate kinematic model. Loveless and Meade (2010) estimated a velocity of about $13 \mathrm{~mm} /$ year at most. In south Sakhalin, Vasilenko and Prytkov (2012) indicated a convergence velocity of $10.0-13.1 \mathrm{~mm} /$ year. These values imply that an almost relative plate convergence strain between the Amur and Okhotsk accumulates along the boundary estimated in this study. Taking a hypothetical time period of 300 years of accumulation of deformations along the boundary, with an estimated mean velocity of $15 \mathrm{~mm} /$ year, we obtain approximately $4.5 \mathrm{~m}$ of relative displacement potential, which corresponds to a potential for an earthquake with $M>7.5$ (Murotani et al. 2008). However, no large earthquakes have been historically recorded in this region (Tamura et al. 2003). The estimated velocity and the duration since the previous large earthquake suggest a high probability of a large earthquake in the near future.

\section{Conclusions}

We estimated the boundary location, convergence velocity, and elastic thickness between the Eurasia (or Amur) and the North American (or Okhotsk) plates in northern Hokkaido in the northernmost part of Japan. The observed GNSS velocity data can be explained well by the dislocation parameters estimated from grid-search procedures. The estimated boundary indicated a north-south strike with east-west compressional strain and is consistent with the geological and seismic boundaries. This suggests that the geological boundary acts as a kinematic plate boundary between the Amur and the Okhotsk plates. The estimated thickness of the elastic layer is consistent with the recorded deep seismic hypocenters and might reflect the lower heat flow in this region. The estimated convergence rate in the northern part also agrees with the plate convergence rate estimated from regional plate motion models. This implies that most of the strain accumulation due to the relative plate motion occurs along the estimated boundary. The non-occurrence of large earthquakes during the past several centuries and the presence of a slow slip event might suggest the presence of a high stress regime in this region. Our estimation suggests successive stress buildup in these active fault zones and a high potential for a large event in the near future.

\section{Acknowledgements}

We used GNSS data provided by the GSI. Hypocenters and mechanisms were obtained from the JMA and GCMT catalogs. The manuscript is improved by critical reviews of Editor Dr. Takuji Yamada and two anonymous reviewers. All figures were drawn using the Generic Mapping Tools (Wessel et al. 2013). This study was partly supported by the Ministry of Education, Culture, Sports, Science and Technology (MEXT) of Japan, under its Earthquake and Volcano Hazards Observation and Research Program, MEXT KAKENHI Grant JP18K19952, and JSPS KAKENHI Grant $19 \mathrm{H} 01984$. 


\section{Authors' contributions}

$\mathrm{Cl}$ was a major contributor for this analysis. $\mathrm{HT}$ and $\mathrm{MO}$ contributed to the interpretation and critically reviewed the manuscript. All authors read and approved the final manuscript.

\section{Funding}

This study was partly supported by the Ministry of Education, Culture, Sports, Science and Technology (MEXT) of Japan, under its Earthquake and Volcano Hazards Observation and Research Program. This study was also supported partly by MEXT KAKENHI Grant JP18K19952, and JSPS KAKENHI Grant $19 \mathrm{H} 01984$.

\section{Availability of data and materials}

The datasets used and/or analyzed during the current study are available from the corresponding author on reasonable request.

\section{Competing interests}

The authors declare that they have no competing interests.

\section{Author details}

${ }^{1}$ Institute of Seismology and Volcanology, Graduate School of Science, Hokkaido University, Sapporo, Japan. ${ }^{2}$ Institute of Seismology and Volcanology, Faculty of Science, Hokkaido University, Sapporo, Japan.

Received: 26 February 2019 Accepted: 24 July 2019

Published online: 02 August 2019

\section{References}

Abe K (1975) Re-examination of the fault model for the Niigata earthquake of 1964. J Phys Earth 23:349-366. https://doi.org/10.4294/jpe1952.23.349

Altamimi Z, Collilieux X, Metivier L (2011) ITRF2008: an improved solution of the international terrestrial reference frame. J Geod 85(8):457-473. https://doi. org/10.1007/s00190-011-0444-4

Bird P (2003) An updated digital model of plate boundaries. Geochem Geophys Geosyst 4(3):1027. https://doi.org/10.1029/2001GC000252

Chapman ME, Solomon SC (1976) North American-Eurasian plate boundary in Northeast Asia. J Geophys Res 81:921-930. https://doi.org/10.1029/JB081 i005p00921

Fukao Y, Furumoto M (1975) Mechanism of large earthquakes along the eastern margin of the Japan Sea. Tectonophysics 25:247-266

Geological Survey of Japan, AIST (ed.) (2015) Seamless digital geological map of Japan 1: 200,000. May 29, 2015 version. Geological Survey of Japan, National Institute of Advanced Industrial Science and Technology

Geospatial Information Authority of Japan (1997) Stain map in Japan. http:// www.gsi.go.jp/cais/HIZUMI-hizumi.html. Accessed on 16 Jul 2019 (in Japanese)

Global CMT Project (2019) Global CMT catalog search. https://www.globalcmt. org/CMTsearch.html. Accessed 16 Jul 2019

Hashimoto C, Noda A, Sagiya T, Matsu'ura M (2009) Interplate seismogenic zones along the Kuril-Japan trench inferred from GPS data inversion. Nat Geosci 2:141-144. https://doi.org/10.1038/NGEO421

Headquarters for Earthquake Research Promotion (2019) Long-term Evaluation https://www.jishin.go.jp/main/choukihyoka/ichiran_pref.pdf. Accessed on 16 Jul 2019 (in Japanese)

Heki K, Miyazaki S, Takahashi H, Kasahara M, Kimata F, Miura S, Vasilenko NF, Ivashchenko A, An K-D (1999) The Amurian Plate motion and current plate kinematics in eastern Asia. J Geophys Res 104:29147-29155. https://doi. org/10.1029/1999JB900295

Itoh Y, Nishimura T (2016) Characteristics of postseismic deformation following the 2003 Tokachi-oki earthquake and estimation of the viscoelastic structure in Hokkaido, northern Japan. Earth Planets Space 68:156. https://doi. org/10.1186/s40623-016-0533-y

Japan Meteorological Agency (2019) Catalog of hypocenter. The Seismological Bulletin of Japan. https://www.data.jma.go.jp/svd/egev/data/bulletin/ hypo_e.html. Accessed on 16 Jul 2019

Jin S, Park PH, Zhu W (2007) Micro-plate tectonics and kinematics in Northeast Asia inferred from a dense set of GPS observations. Earth Planet Sci Lett 257:486-496. https://doi.org/10.1016/j.epsl.2007.03.011
Loveless JP, Meade BJ (2010) Geodetic imaging of plate motions, slip rates, and partitioning of deformation in Japan. J Geophys Res 115:B02410. https://doi. org/10.1029/2008JB006248

Murotani S, Miyake H, Koketsu K (2008) Scaling of characterized slip models for plate-boundary earthquakes. Earth Planets Space 60:987-991. https://doi. org/10.1186/BF03352855

Nakagawa H, Toyofuku T, Kotani K, Miyahara B, Hatanaka Y, Munekane H, Ishimoto S, Yutsudo T, Ishikura N, Sugawara Y (2009) Development and validation of GEONET new analysis strategy (version 4). J Geogr Surv Inst 118:1-8 (in Japanese)

Nakamura K (1983) Possible Nascent Trench along the Eastern Japan Sea as the Convergent Boundary between Eurasian and North American Plates. Bull Earthq Res Inst 58:711-722 (in Japanese)

Nakata T, Imaizumi T (eds) (2002) Digital active fault map of Japan. University of Tokyo Press, Tokyo, p60 (in Japanese)

Ohzono M, Takahashi H, Ichiyanagi M (2015) An intraplate slow earthquake observed by a dense GPS network in Hokkaido, northernmost Japan. Geophys J Int 200:144-148. https://doi.org/10.1093/gii/ggu380

Omuralieva AM, Hasegawa A, Matsuzawa T, Nakajima J, Okada T (2012) Lateral variation of the cutoff depth of shallow earthquakes beneath the Japan Islands and its implications for seismogenesis. Tectonophysics 518:93-105. https://doi.org/10.1016/j.tecto.2011.11.013

Ozawa S, Nishimura T, Suito H, Kobayashi T, Tobita M, Imakiire T (2011) Coseismic and postseismic slip of the 2011 magnitude-9 Tohoku-Oki earthquake. Nature 475:373-376. https://doi.org/10.1038/nature10227

Sagiya T, Miyazaki S, Tada T (2000) Continuous GPS array and present-day crustal deformation of Japan. Pure Appl Geophys 157:2303-2322. https://doi. org/10.1007/PL00022507

Seno T, Sakurai T, Stein S (1996) Can the Okhotsk Plate be discriminated from the North America plate? J Geophys Res 101:11305-11315. https://doi. org/10.1029/96JB00532

Shestakov NV, Gerasimenko MD, Takahashi H, Kasahara M, Bormotov VA, Bykov VG, Kolomiets AG, Gerasimov GN, Vasilenko NF, Prytkov AS, Timofeev VY, Arydyukov DG, Kato T (2011) Present tectonics of the southeast of Russia as seen from GPS observation. Geophys J Int 184:529-540. https://doi. org/10.1111/j.1365-246X.2010.04871.x

Shimazaki K, Zhao Y (2000) Dislocation model for strain accumulation in a plate collision zone. Earth Planets Space 52:1091-1094. https://doi.org/10.1186/ BF03352336

Takahashi H, Kasahara M (2005) Seismic Activity in the Coastal Area of Rumoi Subprefecture and Tectonics in Northern Hokkaido, Japan. Geophysical Bulletin of Hokkaido University 68:199-218. https://doi.org/10.14943/gbhu.68.199 (in Japanese with English abstract)

Takahashi H, Kasahara M, Kimata F, Miura S, Heki K, Seno T, Kato T, Vasilenko NF, Ivashchenko A, Bahtiarov V, Levin V, Gordeev E, Korchagin F, Gerasimenko M (1999) Velocity field of around the Sea of Okhotsk and Sea of Japan regions determined from a new continuous GPS network data. Geophys Res Lett 26:2533-2536. https://doi.org/10.1029/1999GL900565

Tamura M, Kasahara M, Moriya T (2003) The micro-seismicity and crustal structure in the northern part of Hokkaido, inferred from temporal observation. J Seismol Soc Jpn 55:337-350. https://doi.org/10.4294/zisin1948.55.4_337 (in Japanese with English abstract)

Tanaka A (2004) Geothermal gradient and heat flow data in and around Japan (II): Crustal thermal structure and its relationship to seismogenic layer. Earth Planets Space 56:1195-1199. https://doi.org/10.1186/BF0335334

Vasilenko NF, Prytkov AS (2012) GPS-based modeling of the interaction between the lithospheric plates in Sakhalin. Russ J Pac Geol 6:35-41. https://doi. org/10.1134/S1819714012010137

Wei D, Seno T (1998) Determination of Amurian plate motion in mantle dynamics and plate interactions in East Asia. In: M. Flower et al. eds. Geodynam. Series ed. vol 27, pp 337-346

Wessel P, Smith WHF, Scharroo R, Luis JF, Wobbe F (2013) Generic Mapping Tools: improved version released. Eos Trans. AGU 94:409-410. https://doi. org/10.1002/2013EO450001

\section{Publisher's Note}

Springer Nature remains neutral with regard to jurisdictional claims in published maps and institutional affiliations. 